
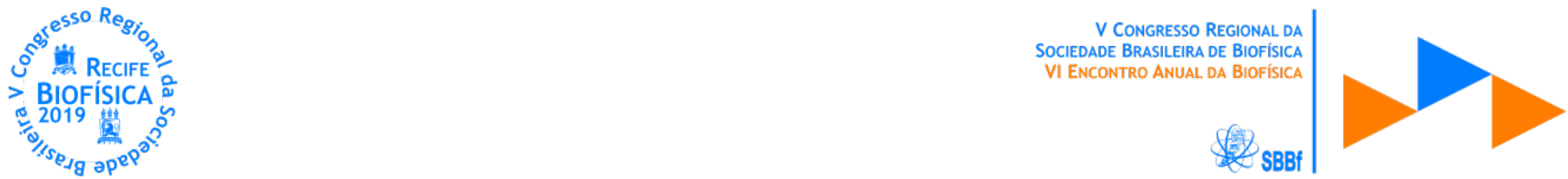

\title{
NANOSSONDAS MAGNETO-FLUORESCENTES PARA APLICAÇÕES BIOMÉDICAS
}

\author{
Isabela Santos Lopes ${ }^{1 *}$, Weslley Felix de Oliveira ${ }^{2}$, Paulo Euzébio Cabral Filho², Giovannia Araujo de Lima Pereira ${ }^{1}$, \\ Adriana Fontes ${ }^{2}$, Mariana Paola Cabrera ${ }^{1,2}$
}

${ }^{1}$ Departamento de Química Fundamental, UFPE; ${ }^{2}$ Departamento de Biofísica e Radiobiologia, UFPE-PE

*Isabela.lopes10.8@gmail.com

\begin{abstract}
RESUMO
Sistemas bimodais são nanoestruturas constituídas por nanopartículas que apresentam propriedades magnéticas e fluorescentes. Nas ciências biomédicas, essas nanoestruturas possuem notáveis aplicações, particularmente, em diagnóstico, sistema de administração de fármacos, próteses e implantes. Por outro lado, há também um grande interesse nas aplicações biomédicas desses sistemas para uso externo, isto é, como sensores de diagnóstico e para a inclusão em instrumentos analíticos utilizados para pesquisa e desenvolvimento de novos medicamentos. Neste contexto, o presente trabalho visou a preparação de sistemas bimodais pela conjugação, via ligação covalente, de nanopartículas de óxidos de ferro em suspensão (ferrofluido, FF) com pontos quânticos (PQs) para serem aplicados no estudo de processos biológicos, bem como agentes de contraste (ACs) em imagem por ressonância magnética (IRM). Inicialmente, o FF foi preparado pelo método de co-precipitação em meio alcalino. Em seguida, o revestimento com polianilina (PANI) sob a superfície do FF (FF@PANI) foi realizado com o intuito de proteger o núcleo magnético de uma possível oxidação e, consequentemente, influenciar na propriedade magnética do FF. $O$ tratamento com PANI também fornece a adição de grupos amina $\left(-\mathrm{NH}_{2}\right)$ na superfície do FF, tornando-o um sistema magnético funcionalizado adequado para a posterior conjugação com os PQs. Nanocristais de telureto de cádmio estabilizados/funcionalizados com ácido mercaptosuccínico (CdTe-AMS) foram sintetizados em meio aquoso. Os sistemas bimodais foram preparados pela conjugação covalente usando carbodiimida entre os PQs e FF@PANI. Na procura de um sistema bimodal altamente fluorescente, com preservação das propriedades magneto-ópticas e estável em suspensão aquosa,
\end{abstract}

vários fatores foram estudados no processo de conjugação. Para isto, foram realizadas variações na quantidade do material FF@PANI, concentração dos PQs (concentrado, e diluições de 6, 4 e 2 ), e concentração dos agentes de acoplamento. A caracterização óptica dos sistemas bimodais foi por espectroscopia de absorção no UV-visível e espectroscopia de emissão. Além disso medidas de potencial zeta também foram realizadas para avaliar o processo de modificação de superfície. Ainda devido à propriedade paramagnética do sistema bimodal (FF@PANI-CdTe-AMS), medidas de relaxividade foram realizadas para avaliar os sistemas magnéticos como possíveis ACs negativos. Nossos resultados iniciais revelaram um deslocamento do máximo do comprimento de onda de emissão (red shift) para os sistemas bimodais, indicando que houve uma mudança na superfície ativa dos PQs pela conjugação com o FF@PANI. As medidas de potencial zeta demonstraram o sucesso da preparação das nanossondas magneto-ópticas. 0 sistema FF@PANI apresentou um valor positivo $(+22 \mathrm{mV})$ e após a adição dos PQs foi observada uma mudança para valores negativos (-26 $\mathrm{mV}$ ) devido à presença dos grupos carboxílicos do AMS na superfície dos PQs. Foi verificado um melhor desempenho dos sistemas magnéticos para atuarem como ACs negativos devido à melhor taxa de relaxação quando comparada com o da água. Ressalta-se que todos os sistemas bimodais mostraram uma boa estabilidade em meio aquoso e preservaram suas propriedades magnéticas e fluorescentes pelo menos até 15 dias. Os autores acreditam que as nanossondas bimodais obtidas são promissoras e podem ser utilizadas para a conjugação de biomoléculas tornando-as possíveis nanossondas magneto-ópticas-sítio específicas para aplicações biomédicas. 